\title{
Calibration of Hydrological Streamflow Modeling Using MODIS
}

\author{
Manithaphone Mahaxay ${ }^{1}$, Wanchai Arunpraparut ${ }^{2}$, Yongyut Trisurat ${ }^{3}$ and Nipon Tangtham ${ }^{4}$ \\ 1.Watershed and Environmental Management Division, Department of Conservation, Kasetsart University, Bangkok 10900, \\ Thailand \\ 2. Department of Forest Engineering, Kasetsart University, Bangkok 10900, Thailand \\ 3. Department of Forest Biology, Kasetsart University, Bangkok 10900, Thailand \\ 4. Forest Research Center, Kasetsart University, Bangkok 10900, Thailand
}

\begin{abstract}
LULC (land use and land cover) plays an important role in mathematical hydrological modeling. As many countries, available LULC are not always updated to reflect the most current situation. In this regard, the objective of this study was to investigate the potential capability of moderate resolution satellite imagery such as MODIS (Moderate Resolution Imaging Spectroradiometer), acquired in 2010 for updated LULC. This issue was illustrated through the application of the most current LULC as one of the data inputs of the SWAT (Soil and Water Assessment Tool) model in the Tonle Sap Lake Basin, a sub-basin of the Mekong River. The streamflow was tested using moderate resolution LULC of 500 meters. The statistical evaluation results at a monitoring station for model calibration and validation showed that the $R^{2}$ for daily and monthly values range from 0.76 to 0.88 and 0.86 to 0.89 respectively, whereas the Nash-Sutcliffe efficiency daily and monthly values range between 0.75 to 0.85 and 0.76 to 0.87 respectively. The simulation result based on MODIS imagery demonstrates LULC at moderate resolution holds considerable potential as an effective hydrological modeling tool. An additional level of confidence is provided by the notion that the methods described here could be applied in similar watershed conditions.
\end{abstract}

Key words: LULC (land use and land cover), MODIS, SWAT (Soil and Water Assessment Tool), modeling, streamflow.

\section{Introduction}

LULC (land use and land cover) dataset, which is important in a watershed for hydrological and environmental modeling, require accurate LULC datasets to parameterize the physical system being simulated [1]. It is important that land-cover data be based on the most current data available, since the land-cover changes over time [2]. In watersheds, where LULC change takes place over the modeling period, using a single land-use geospatial data is not a true representation of the watershed condition [3]. The LULC data are one of the essential inputs for SWAT (Soil and Water Assessment Tool) model to which this research was applied.

Corresponding author: Manithaphone Mahaxay, Ph.D., research fields: watershed management, remote sensing and GIS. E-mail: manithaphone@gmail.com.
SWAT is considered one of the most suitable physically-based models for simulating hydrological condition and is one of the most widely used watershed-scale water-quality models in the world. Nearly 600 peer-reviewed SWAT-related journal articles have been published and hundreds more have been published in conference proceedings and other formats [4]. Rossi et al. [5] pointed out that SWAT can potentially be used as an effective water quantity tool within Mekong basin. In which, SWAT model has been setup to simulate streamflow in each Mekong sub-basin [6]. In the Mekong Sub-basin the SWAT model has been calibrated using the most up-to-date available land use data of 2003 generated from Landsat image against available streamflow data for the period 1985-2000 [7]. The SWAT simulation result provided daily estimates of flow for 138 sub-basins covering 
entire the Lower Mekong basin except the delta south of Phnom Penh [6]. However, whether using simple or complex models, an accurate LULC dataset with an appropriate spatial or temporal resolution and level of detail is paramount for reliable predictions [8].

Landsat imagery is widely used to produce high resolution LULC data covering large river watershed. Although high resolution satellite imagery data can be extremely useful for LULC change detection and monitoring efforts, it can be difficult to obtain an image over the entire study area during a particular timeframe. In other words, only it is rarely possible to generate more than one scene of high resolution satellite imagery in a day. The revisit characteristics of the satellites, as well as the presence of cloud cover, can limit the availability of data [9]. In addition, spatial data, including land use, are usually expensive to obtain. This paper explores alternatives aimed at overcoming the limitations of LULC for hydrological modeling. To achieve the overall goal of the research, the status of LULC in 2010 was mapped out using both GIS (Geographic Information System) analysis and remote sensing data such as MODIS (Moderate Resolution Imaging Spectroradiometer) with $500 \mathrm{~m}$ resolution. The principle objective of this study is to assess whether free-data-MODIS can be effectively applied as an input for hydrological modeling. It is expected that the results of this study will contribute useful hydrologic information regarding the possibility of moderate-resolution of LULC data for large river watershed assessments.

\section{Study Area}

Tonle Sap Lake Basin is located in the northwest of Cambodia, between approximately latitudes $102^{\circ} 15^{\prime}$ to $105^{\circ} 50^{\prime} \mathrm{E}$ and longitudes $11^{\circ} 40^{\prime}$ to $14^{\circ} 28^{\prime} \mathrm{N}$. The Tonle Sap Lake Basin is a sub-catchment of the Mekong basin. The total drainage area of Tonle Sap Lake Basin is approximately $85,786 \mathrm{~km}^{2}$, including a permanent lake area of around $2,350 \mathrm{~km}^{2}$. That is approximately $10.8 \%$ of the total area of the Mekong basin [10]. The majority of the catchment is located in Cambodia and only 5\% is in Thailand (Fig. 1). Ground altitudes range from $1 \mathrm{~m}$ to $1,500 \mathrm{~m}$ above sea level. About one third of the area is covered by forests that consist of a mixture of deciduous trees. There are agricultural areas and numerous small settlements as well.

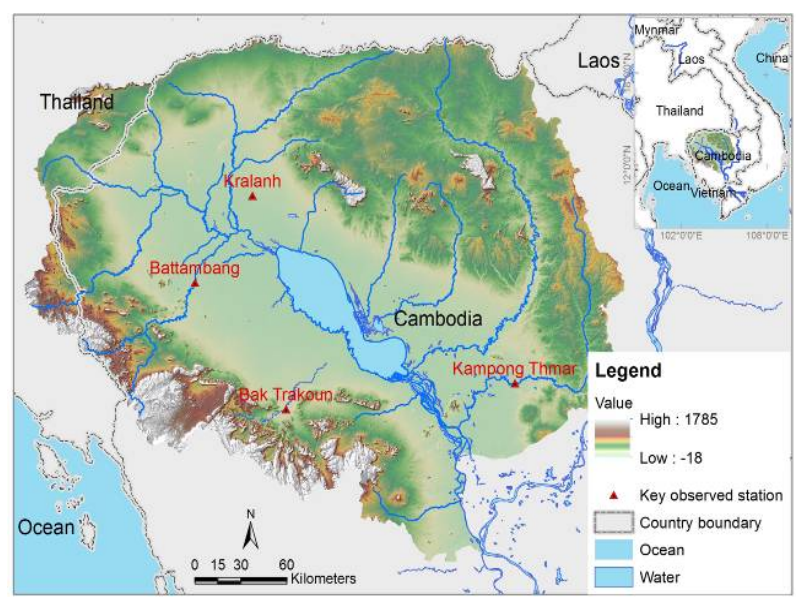

Fig. 1 Tonle Sap watershed.

\section{Materials and Methods}

\subsection{Materials}

Time series of 16-day composite MODIS imagery of MOD09A1 with $500 \mathrm{~m}$ resolution was acquired for LULC classification and mapping of spatial LULC of 2010. The other spatial data used are soil map of $50 \mathrm{~m}$ resolution based on FAOIUNESCO [11] classification system up to level three category and DEM (Digital Elevation Model)data of $50 \mathrm{~m}$ resolution. The other hydro-climatological quantities have been used from available gauges over the study area. Fig. 2 shows sets of required spatial data for SWAT hydrological modeling.

Most of the data preparation and analysis in this research was carried out using ArcGIS 10.1. Some specific image processing operations were executed using the ERDAS (Earth Resource Data Analysis System) Imagine software Version 8.0 (ERDAS Imagine is a remote sensing application designed for geospatial applications). 


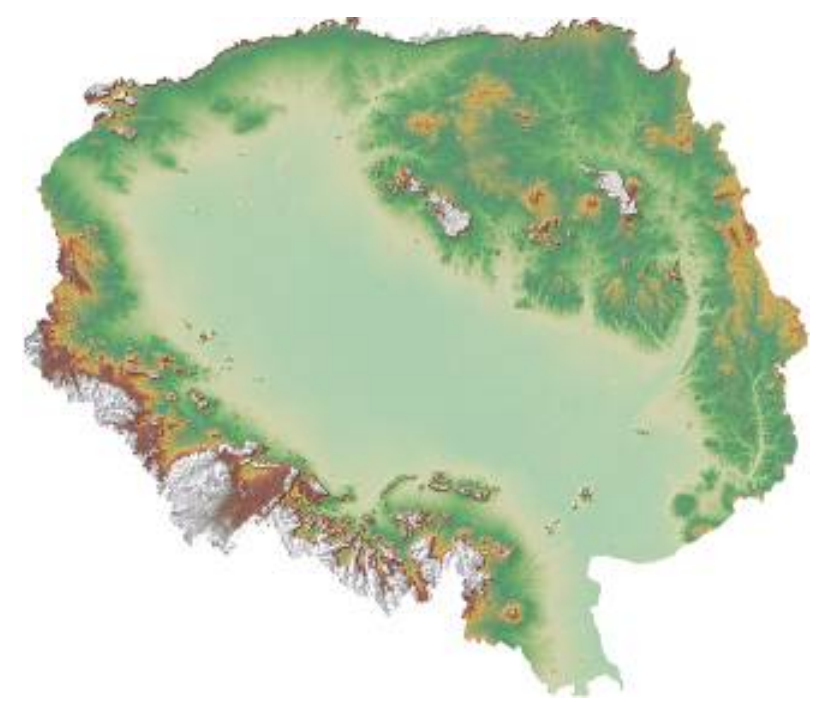

(a)

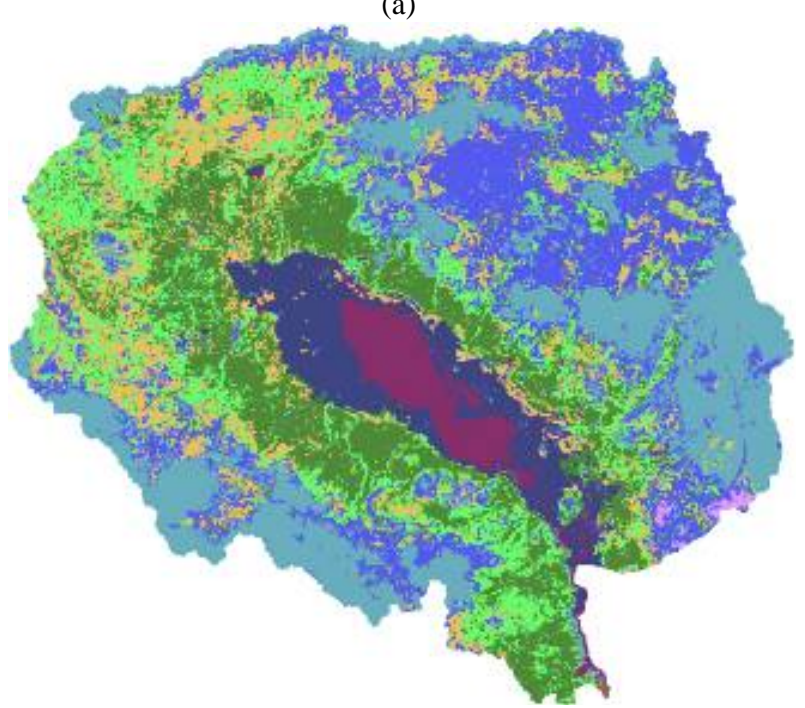

(b)

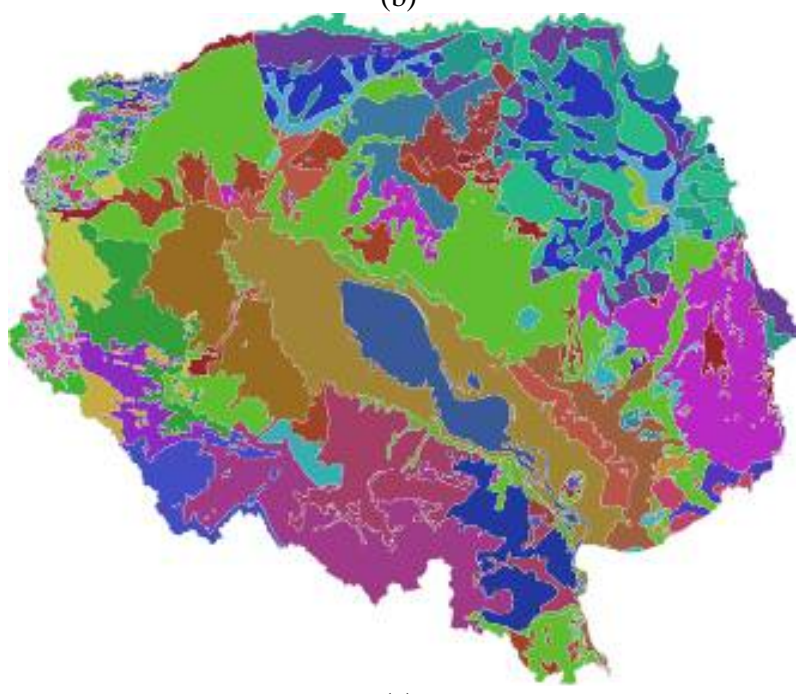

(c)

Fig. 2 Spatial data for SWAT model input: (a) DEM; (b) Land use; (c) Soil.
Other types of software employed are ArcSWAT Version 2012.10_1.7 for streamflow modeling and MRT (MODIS Reprojection Tool) for MODIS reprojection and transformation.

\subsection{Methods}

SWAT is a model developed by the USDA-ARS (United States Department for Agriculture, Agricultural Research Service). The main components of SWAT include hydrology, weather, sedimentation, soil temperature, crop growth, nutrients, pesticides and agricultural management. The model can be used to predict impacts of land management practices on water, sediment and agricultural chemicals in catchments [12, 13]. The SWAT model simulates hydrology as a two-component system, composed of land hydrology and channel hydrology. The land portion of the hydrologic cycle is based on a water mass balance. Soil water balance is the primary consideration by the model in each HRU (hydrological response unit), which Arnold et al. [14] represent as follow:

$$
S W_{t}=S W+\sum_{i=1}^{t}\left(R_{i}-Q_{i}-E T_{i}-P_{i}-Q R_{i}\right)(1)
$$

where, $S W$ is the soil water content; $i$ is time in days for the simulation period $t$; and $R, Q, E T, P$ and $Q R$ respectively are the daily precipitation, runoff, evapotranspiration, percolation and return flow.

LULC data used for this hydrological modeling were derived from satellite MODIS imagery. The LULC classification of 2010 LULC was carried out using supervised classification and every training site was carefully selected. Post-classification was performed based on existing land use map of 2003 generated from Landsat, DEM and ground survey. Accuracy assessment was also executed based on those field surveys and existing land use data. Overall classification accuracy was greater than $80 \%$ [15]. To make LULC data useable for SWAT, ArcSWAT interface requires a table linking the values represented to LULC types already defined in the model. Hence, the look-up table that converts the 
LULC classification codes to SWAT land cover/plant codes was created manually in "ASCII.txt" format. Table 1 represents a look-up table for LULC categories conversion.

Table 1 Look-up table for the land use database use in SWAT.

\begin{tabular}{llll}
\hline \multicolumn{2}{l}{ Land use and land cover class } & $\begin{array}{l}\text { Land use } \\
\text { class No. }\end{array}$ & $\begin{array}{l}\text { SWAT } \\
\text { database }\end{array}$ \\
\hline Forest land & Evergreen & 1 & FRSE \\
& Deciduous & 2 & FRSD \\
& Plantation & 3 & PLAN \\
& Shrubland & 4 & SHRB \\
Crop land & Upland & 5 & AGRL \\
& Lowland paddy & 6 & PDDY \\
\multirow{5}{*}{ Others } & Wetland & 7 & WETL \\
& Built-up land & 8 & URBN \\
& Water (rivers, lakes) & 9 & WATR \\
\hline
\end{tabular}

The soil units were also translated into SWAT user soil database. ArcSWAT creates the hydrologicresponse unit by combining DEM (Digital
Elevation Model), soil and slope. Once DEM, land use and land cover, and soil data have been overlaid, the HRUs (hydrological Response Units) were generated. Rainfall data from 31 stations with time-series data from 1980 to 2008 were used as input data in SWAT. Additional rainfall data related to 2009 and 2010 were compensated by Global Weather Data for SWAT athttp://globalweather.tamu.edu/.

When all inputs were successfully entered, simulation was activated. Sensitivity analysis was carried out for help in determining the sensitivity of parameters by comparing variances in output caused by variability in the inputs. It also facilitates the selection of important and influential parameters for a model calibration by indicating the parameters that display higher sensitivity in output due to input variability. Streamflow simulations were calibrated using LULC in 2010. Overall procedure of SWAT application in this research is shown in Fig. 3.

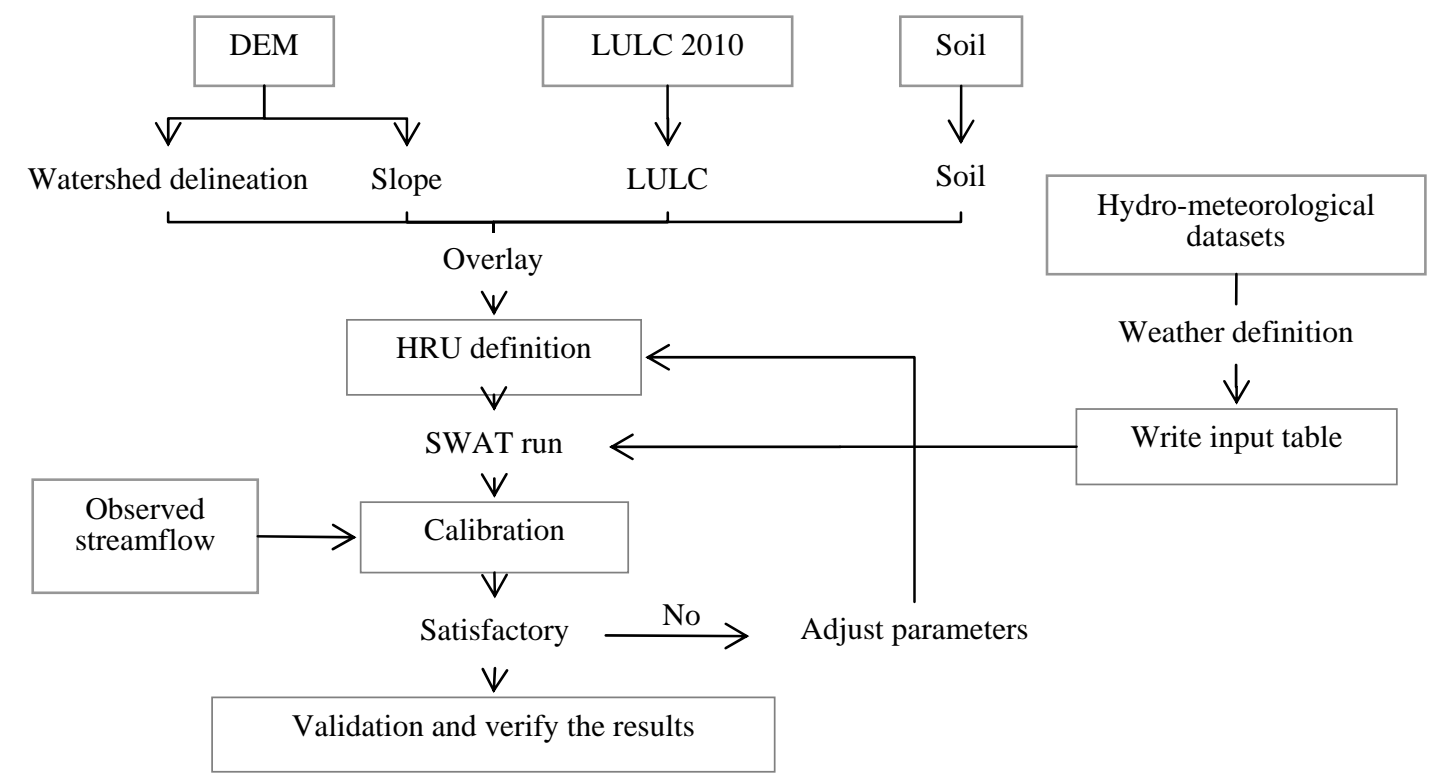

Fig. 3 Flow chart of streamflow modeling process.

The streamflow was run at the outlet of selected hydrological stations at daily and monthly time steps for the period January through December 2010. Calibration was performed on the 1997 to 2009 years, while the years from 1980 to 1996 were used for model warm-up period. To verify the results, the performance of the model in simulating streamflow was evaluated using ENS or NSE or $E_{N S}$ (Nash-Sutcliffe efficiency) and the coefficient of determination $\left(R^{2}\right)$ [16]. The Nash-Sutcliffe statistic is a measure of how well the observed variance is simulated [17]. The equations used were as follows: 


$$
E_{N S}=1-\frac{\sum_{i=1}^{n}\left(O_{i}-P_{i}\right)^{2}}{\sum_{i=1}^{n}\left(O_{i}-\bar{O}\right)^{2}}
$$

where, $O_{i}$ and $P_{i}$ are the observed and simulated data, respectively; $\bar{O}$ is the average of the observed data and $n$ is the total number of data records.

$$
R^{2}=1-\frac{\sum\left(Y_{i}-\hat{Y}_{i}\right)^{2}}{\sum\left(Y_{i}-\bar{Y}\right)^{2}}
$$

where, $Y_{i}$ denotes the value of the ith dependent

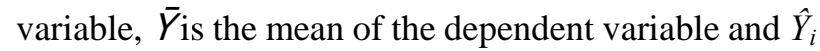
is the $i t h$ fitted value.

\section{Results and Discussion}

\subsection{Sensitivity Analysis}

Sensitivity analysis has been carried out for each available observed streamflow data of each LULC SWAT project. SUFI2 (Sequential Uncertainty Fitting)

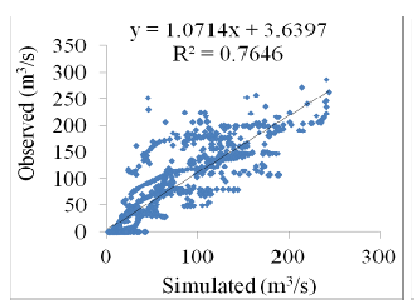

$$
\text { (a) }
$$

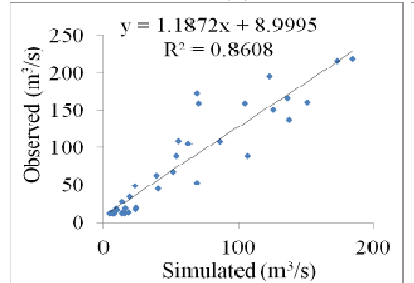

(e)

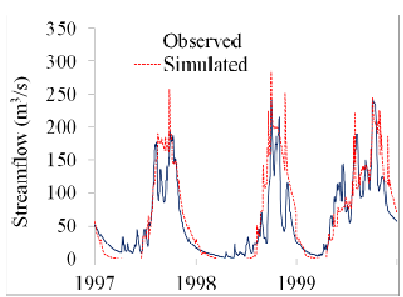

(b)

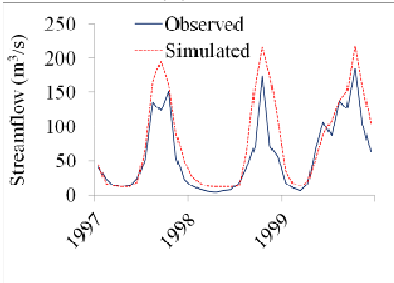

(f) for the calibration of uncertainty in procedure was used for this analysis. Five parameters were found to be sensitive, with relative sensitive values in the range of 0.031 to 0.034 . The most sensitive parameters are threshold depths of water in the shallow aquifer for "revap” to occur (REVAPMN.gw), Alpha_Bf factor (base flow alpha), Gw_Revap coefficient (groundwater “revap”), ESCO factor (soil evaporation compensation), initial SCS CN2 value (Curve Number II) respectively. These sensitive parameters were considered for model calibration. The remaining parameters had no significant effect on streamflow simulations. Changes in their values do not cause significant changes in the model output.

\subsection{Calibration and Validation for Streamflow}

\section{Estimation}

Hydrological streamflow results for the observation station at Kampong Thmar gauge is being discussed (Fig. 4).

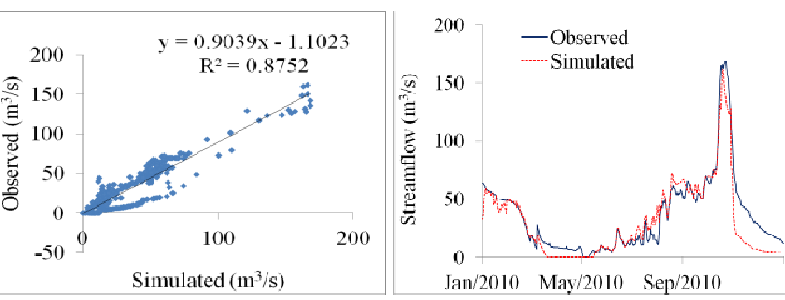

(c)

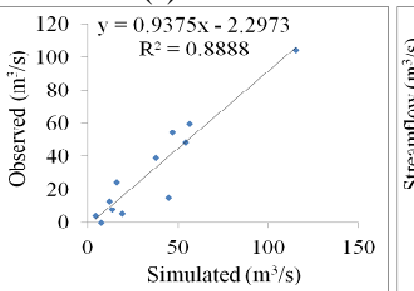

(g) (d)

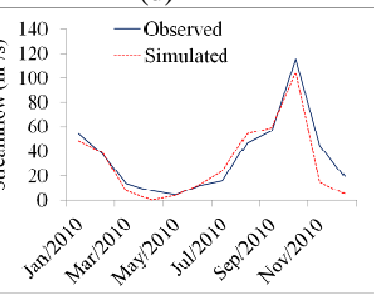

(h)

Fig. 4 Simulation results: (a) and (b)—Daily calibration result; (c) and (d)—Monthly calibration result; (e) and (f)—Daily validation result; (g) and (h)—Monthly validation result.

The monthly calibration results have shown better agreement between monthly observed and simulated flows in both calibration and validation processes. The result of the $E_{N S}$ and $R^{2}$ are as high as 0.88 and 0.89 respectively (Table 2). Based on the statistical analysis of model evaluation results, conclusion of whether MODIS can be effectively applied as an input to
SWAT interface for hydrological streamflow modeling is noticeable.

Table 2 Calibration and validation results.

\begin{tabular}{lllll}
\hline & \multicolumn{2}{c}{ Calibration } & \multicolumn{2}{c}{ Validation } \\
\cline { 2 - 5 } & $E_{N S}$ & $R^{2}$ & $E_{N S}$ & $R^{2}$ \\
\hline Daily & 0.75 & 0.76 & 0.85 & 0.88 \\
Monthly & 0.76 & 0.86 & 0.87 & 0.89 \\
\hline
\end{tabular}


However, according to Benaman et al. [18], model simulation can be judged as satisfactory if $R^{2}$ is greater than 0.6 and $E_{N S}$ is greater than 0.5. Hence study results agree reasonably well with these accuracy simulations of LULC parameters. Some of the model inaccuracy are caused due to data gaps and lack of accurate and efficient input data where is available such as rainfall, temperature and evapotranspiration. Hence, to increase model efficiency it is obviously depending on such data inputs, as well suitable distribution of the measuring stations over the watershed is required.

\section{Conclusions}

Model produced good simulation results for daily time steps which have demonstrated that moderate resolution of non-commercial and freely-available satellite imagery like MODIS holds considerable potential for application in hydrological modeling. However, the use of other hydrological models would be more beneficial for the hydrological modeler in order to enhance our understanding of alternative MODIS-based LULC as an input parameter for hydrological modeling. In addition to the modeling tool, the assessment of LULC data input capability would be more beneficial if simulation is tested by a number of hydrological parameters other than streamflow, such as surface run-off, water quality, etc.

\section{Acknowledgment}

The authors would like to express their appreciation to colleagues from the Department of Water Resources in Cambodia and the Mekong River Commission Secretariat for facilitating and providing data for this research. Special thanks to Dr. Lia Genovese for editing this manuscript.

\section{References}

[1] Burian, S., Brown, M., and McPherson, T. 2002. "Evaluation of Land Use and Land Cover Datasets for Urban Watershed Modeling." Water Science and Technology 45 (9): 269-76.
[2] Chen, P., Luzio, M. D., and Arnold., J. G. 2005. “Impact of Two Land-cover Data Sets on Streamflow and Total Nitrogen Simulations Using A Spatially Distributed Hydrologic Model." Presented at the ASPRS 2005-Pecora 16 "Global Priorities in Land Remote Sensing” Sioux Falls, South Dakota, USA.

[3] Pai, N., and Saraswat, D. 2011. "SWAT2009_LUC: A Tool to Activate the Land Use Change Module in SWAT 2009." Transactions of the American Society of Agricultural and Biological Engineers 54 (5): 1649-58.

[4] Gassman, P. W., Arnold, J., Srinivasan R., and Reyes, M. 2010. "The Worldwide Use of the SWAT Model, Technological Drivers, Networking Impacts, and Simulation Trends." Presented at the 21st Century Watershed Technology, Improving Water Quality and Environment Conference Proceedings, Universidad EARTH, Mercedes, Costa Rica.

[5] Rossi, C. G., Srinivasan, R., Jirayoot, K., Duc, T. L., Souvannabouth, P., Bin, N., and Gassman, P. W. 2009. "Hydrological Evaluation of the Lower Mekong River Basin with the Soil and Water Assessment Tool Model." International Agricultural Engineering Journal (18): 1-13.

[6] Mainuddin, M., Hoanh, C. T., Jirayoot, K., Halls, A. S., Kirby, M., Lacombe, G., and Srinetr, V. 2010. "Adaptation Options to Reduce the Vulnerability of Mekong Water Resources, Food Security and the Environment to Impacts of Development and Climate Change.” CSIRO, Water for a Healthy Country National Research Flagship: 152.

[7] Johnston, R., Rowcroft, P., Hortle K. G., and McAlister, C. 2003. "Hydrological Models of the Lower Mekong Basin at MRC.” Presented at the Workshop on Integrating Environmental Impacts into Water Allocation Models of the Mekong River Basin, University of Economics, Ho Chi Minh City, Vietnam.

[8] Huang, J., Zhou, P., Zhou. Z., and Huang, Y. 2013. “Assessing the Influence of Land Use and Land Cover Datasets with Different Points in Time and Levels of Detail on Watershed Modeling in the North River Watershed, China." International Journal of Environmental Research and Public Health (10): 1660-4601.

[9] WRP (Wetlands Research Program). 1994. The Corps of WRP (Wetlands Research Program). 2004. "Remote Sensed Data, Information for Monitoring Dynamic Wetland Systems.” Remote Sensing/GIS Support Center, U.S. Army Cold Regions Research and Engineering Center. Accessed Nov 1, 2013. http://el.erdc.usace.army.mil/elpubs/pdf/wgsw2-1.pdf.

[10] MRC (Mekong River Commission). 2003. State of the Basin Report. Executive summary. 
[11] FAO. 1988. FAO/UNESCO Soil Map of the World, Revised Legend, with Corrections and Updates. World soil resources report 60, FAO, Rome.

[12] Neitsch, S. L., Arnold, J. G., Kiniry, J. R., and Williams, J. R. 2009. Soil and Water Assessment Tool. Theoretical Documentation, Version 2000. Texas, USA: USDA Agricultural Research Service and Texas A \& M Blackland Research Center.

[13] Chaplot, V., Saleh, A., and Jaynes, D. B. 2004. "Predicting Water, Sediment and $\mathrm{NO}_{3}-\mathrm{N}$ Loads under Scenarios of Land-Use and Management Practices in a Flat Watershed." Water, Air, \& Soil Pollution (154): 271-93.

[14] Arnold, J. G., Srinivasan, P., and Muttiah, R. S. 1998. "Large Area Hydrologic Modeling and Assessment. Part I. Model Development.” The Journal of the American Water
Resources Association (JAWRA) 34: 73-89.

[15] Mahaxay, M. 2014. "Evaluation of MODIS Through Its Application in Land Use and Land Cover Change Effect on Streamflow: Tonle Sap Basin, Cambodia.” Ph.D. thesis, Kasetsart University.

[16] Eisenhauer, J. G. 2003. "Regression through the Origin.”Teaching Statistics 25 (3):76-80.

[17] Nash, J. E., and Sutcliffe, J. 1970. "River Flow Forecasting through Conceptual Models. Part I-A Discussion of Principles.” Journal of Hydrology 10 (3): 282-90.

[18] Benaman, J., Christine, A. S., and Douglas, A. H. 2005. "Calibration and Validation of Soil and Water Assessment Tool on An Agricultural Watershed in Upstate New York.” Journal of Hydrologic Engineering 10 (5): 363-74. 